\title{
“STUDIES ON INFLUENCE OF LIQUID LEVEL ON BLAST FURNACE PERFORMANCE AND MONITORING OF HEARTH DRAINAGE"
}

\author{
Dr. Baidya Nath Roy ${ }^{1}$ and Uddeshya Kumar ${ }^{2}$
}

\begin{abstract}
For the stability in operation and durability in blast furnace campaign life, the draining time optimization is a very important factor. For this purpose, the extent of liquid level in hearth representing the slag and hot metal occupancy should be estimated on continuous basis. The increased liquid levels in the hearth affect the smooth operations occurring in the blast furnace by exerting an upward force on the submerged coke deadman resulting in slow down of burden descent and disturbance in the blast pressure. To avoid any irregularity, the hearth liquid level should be kept under control and liquid iron and slag must be removed at a rate which does not allow any hazardous effect. This necessitates the precise and real time analysis of liquid products in hearth. But the direct measurement technique of this level in the hearth is unavailable due to high temperature and pressure inside the blast furnace. In order to analyse it, indirect approaches have been developed which determines the accumulation of molten metal and slag in the hearth on the basis of estimated hot metal and slag influx using chemical mass balance, draining rate of molten metal calculated by the filling level of torpedoes using radar sensors, outflow rate of slag through the slag granulation plant and geometry of hearth. The paper deals with the effects as well as dependency of liquid level on the blast furnace performance and the other process parameters and its measurement along with the action standards to control it.
\end{abstract}

Keywords: hearth occupancy, permeability resistance, voidages, deadman zone, tuyeres.

\section{INTRODUCTION}

The blast furnace operation includes chemical reduction and physical conversion of oxides of iron into liquid iron called hot metal. The blast furnace is charged with iron ore, coke and limestone from the top and preheated air with enriched oxygen is blown through the tuyeres. The dumped raw materials require 6 to 7 hours to descend through the furnace to the bottom followed by a series of intermediate steps in different zones and finally become liquid slag and liquid iron as products resting in the voidage of coke bed in hearth till these products are cast at periodic intervals through tap holes provided to the furnace. When the productivity of the furnace exceeds the tapping rate and the stream of exiting melts has a low outflow rate, the products hot metal and slag increase in the hearth and the hearth occupancy rises. Exceeding certain critical level has a direct impact on the on-going operations. The hearth liquids exert an upward force to the deadman coke and this force causes disturbance in internal pressure and erratic burden descent. That's why the liquid levels in the hearth are needed to be kept as low as possible and the hearth should not be used as a buffer for containing condensed phases.

\footnotetext{
${ }^{1}$ Asstt. Prof., Metallurgical Engg. Deptt. B.I.T. Sindri (Dhanbad), Jharkhand, 828123, India.

${ }^{2}$ B. Tech Final Year, Metallurgical Engg. B.I.T. Sindri (Dhanbad), Jharkhand, 828123, India.
} 


\section{EFFECTS OF INCREASED LIQUID LEVEL}

Continuously rising liquid levels in the hearth can affect the BF processing in following ways:

- $\quad$ The upward force will be too high and consequently the maximum pressure difference over the burden that allows the smooth operation will exceed and the burden descent will become erratic, causing frequent hanging, slipping and chilling.

- The tuyeres reaching slag level can severely affect the gas flow, flowing against the furnace wall and the wall temperatures all the way up to stack will increase subjecting the cooling elements to a higher heat load than they usually encounter. It may result in heat and furnace efficiency loss leading to furnace cooling.

In this case the furnace should be cast without delay and actions should be taken to restore furnace stability.

- $\quad$ The risen liquid level causes the blast to be deflected towards the wall, rather than through the centre of the furnace, as the coke in front of the tuyeres has been infiltrated with slag, and so is much less able to accept the flow of the gases produced at the raceway. Thus bosh will be subjected to higher heat loads than normal.

- The slag can be blown high up in the active coke zone, impeding normal gas distribution and can affect the gaseous reduction of the burden resulting in a chilling furnace.

- The high hot metal level can cut tuyere causing water leakage into the furnace, blowpipe fail or tuyere burn which can lead to blow-out of coke and a very critical emergency stop.

- $\quad$ The extra time spent by melts in the hearth results in extra heat and radiation losses which consequently does more erosion damage to the refractory lining of the walls of the blast furnace.

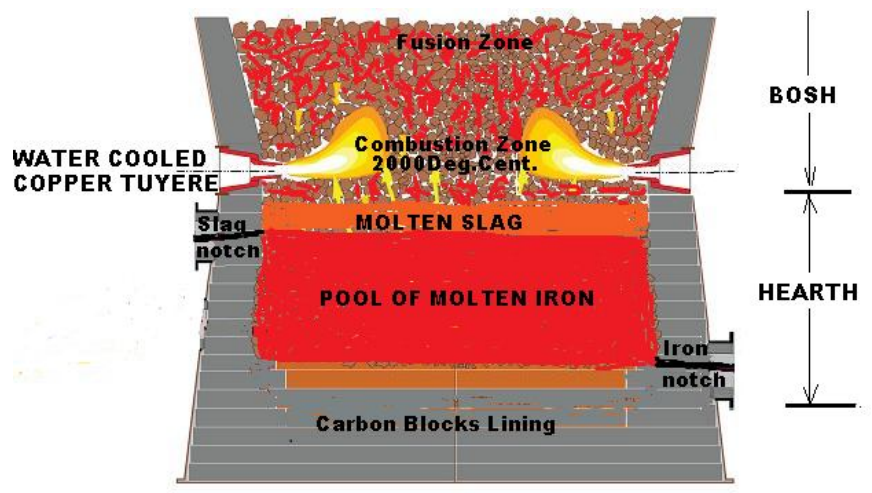

Figure1. Schematic view of liquid levels in the hearth prior to tapping

\section{METHODOLOGY}

\section{Modelling of Liquid level and hearth drainage system}

The analysis and computer modelling of reaction kinetics involved in iron making have been developed, since the direct measurement technique of hearth liquid level is unavailable. The hearth occupancy can be estimated by mathematical \& mass-energy balance models which, based on general metallurgical principles and mathematical equations, simulate the blast 
furnace phenomena in segments i.e. charging, blowing and tapping on real time basis. The models extract plant data quantitatively like temperature, pressure, velocity, distance, etc. from the field devices and then convert them into trends using metallurgical principles. The first stage of estimation refers to the interval between closing of last casting and release of the current casting. The hot metal and slag production rates are estimated using charge rate of raw materials and their compositions. A radar system measures the rate of filling of hot metal produced in torpedo. The amount of slag is calculated by weighing granulated slag. The difference between calculated product and outflow rate represents the accumulated liquid products in hearth. Liquids rest in the bottom void fraction of the hearth, so the hearth geometry is also taken into consideration to evaluate liquid volume content and hence liquid level is estimated on the real time basis.

\section{Correlational studies with respect to process parameters}

Hearth occupancy or liquid level affects many operational elements. For effective control over the parameters before they pose any threat to the blast furnace performance, it is necessary to have a better understanding of mutual correlation between them in order to maintain smooth production of hot metal and stable burden descent. To analyse the dependency and impacts caused, study and correlational research of hearth liquid level with respect to various process parameters and were done for a certain period:

Permeability in different zones, \% Si content in the hot metal, hot metal temperature, heat loss in bosh region, top gas temperature, stock level, no. of casts per day, cold blast flow, cold blast pressure, hot blast pressure, drill diameter, coke rate and casting speed.

\section{RESULTS AND DISCUSSIONS}

The regression analysis with respect to following process parameters was found to be in good correlation with the liquid level in hearth. The correlations with those parameters along with the theoretical elaboration are given below:

\section{- $\quad$ Permeability resistance (K):}

The permeability of a blast furnace is given by the term permeability resistance. It has been divided into 3 parts as upper, middle and lower regions of blast furnace. The total permeability is simply the sum of permeability in 3 regions.

Permeability in the lower region of blast furnace has a great effect on the performance of the blast furnace as it determines the wind acceptability of the BF and hence the productivity. When the tap hole is closed, the amounts of slag and hot metal start building up in the BF. These liquids exert buoyant force to the deadman which tends to float up. This movement exerts influence on the gas flow and thus the permeability gets disturbed. The pressure drop increases with an increased level (which is often maximum at the beginning of tapping and lowest when hearth has been drained). 


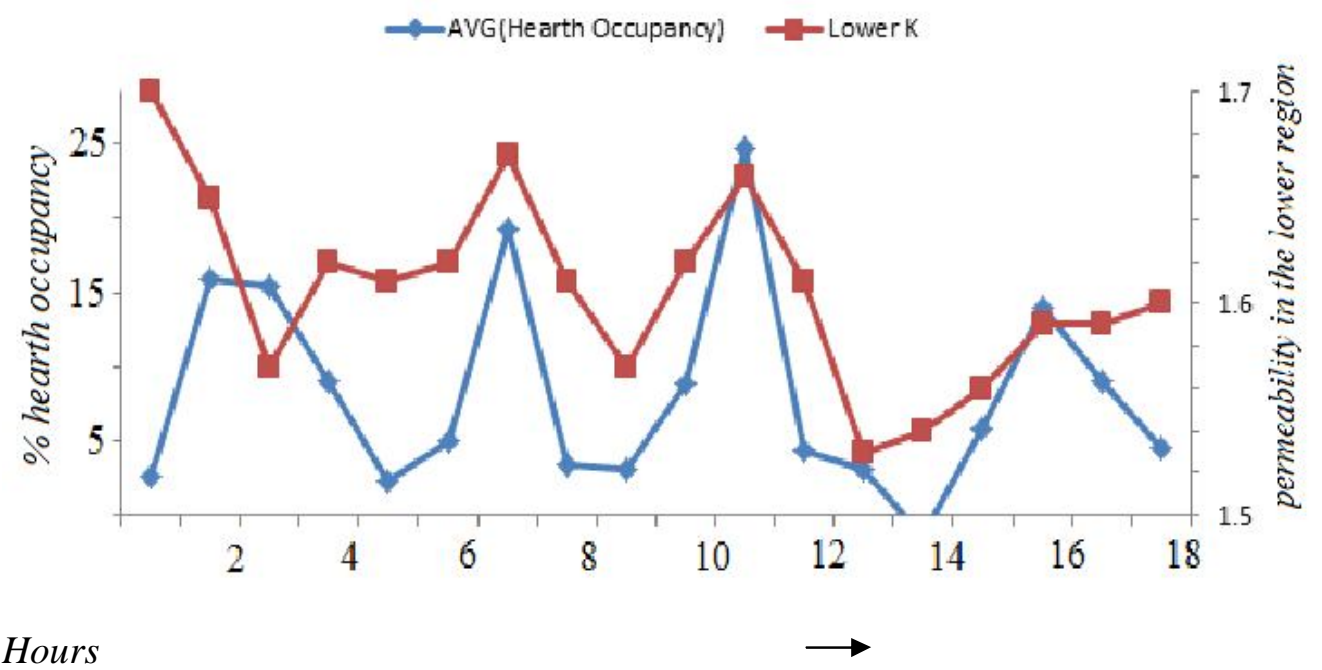

Figure2. Variation of permeability in the lower region with average hearth occupancy

\section{- Heat loss in bosh region}

Higher the amount of products in the hearth disturbs the blast flow direction, deflecting it to the walls rather than through central flow. The coke in front of the tuyeres has been infiltrated with slag, and so is much less able to accept the flow of the gases produced at the raceway. As a consequence the large amount of heat is lost rather being used in reduction of the charged raw materials. Thus bosh is subjected to higher heat loads than usual.

\section{- $\quad$ Silicon content in hot metal}

Silicon comes in the hot metal from the ash of the coke and coal. Silicon oxide gets reduced via direct reduction in following steps:

Gaseous $\mathrm{SiO}$ is formed in the raceway. The first reduction occurs at the very high raceway flame temperatures. Now the reduction takes place by the direct reduction with iron as

$$
\mathrm{SiO}+[\mathrm{C}] \longrightarrow[\mathrm{Si}]+\mathrm{CO}
$$

where square brackets represent solution in iron.

The silicon of the hot metal is in equilibrium with the slag. When the droplets of iron pass through the slag layer, $\mathrm{Si}$ can reoxidise with the $\mathrm{FeO}$ of slag as,

$$
[\mathrm{Si}]+2(\mathrm{FeO})+2[\mathrm{C}] \rightarrow\left(\mathrm{SiO}_{2}\right)+2[\mathrm{Fe}]+2 \mathrm{CO}
$$

If there is a higher contact between iron and gas, it leads to higher temperature and allows more $\mathrm{SiO}$ gas to react with the carbon in the hot metal and consequently results in higher $\mathrm{Si}$ content of hot metal. This implies that high level of melts corresponds with high hot metal silicon. The correlational research validates the hypothesis. 


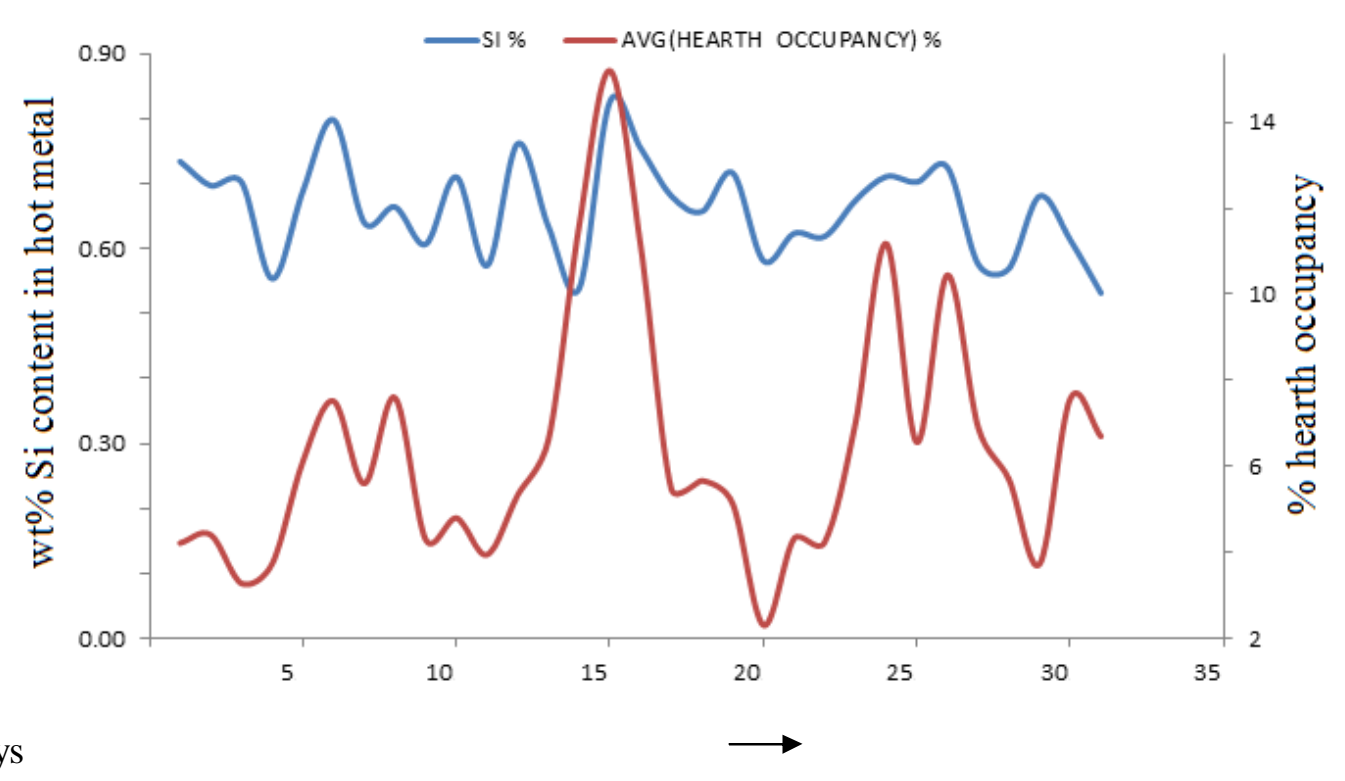

Figure3. Variation of Si content in hot metal with hearth occupancy

\section{- $\quad$ Stock Line}

The burden decent in the blast furnace is observed with the help of stock rods, which rest on the burden surface and descend with the charged burden. A stock rod is the direct representative of smoothness or erratic descending of charged materials. The burden descent demands the availability of voidages in the blast furnace. These voidages are created by different means like consumption and gasification of coke, melting of initially charged burden etc.

A smooth burden descent takes place When the downwards forces (like weight) of the charged materials exceed the counteracting upward forces. The upward forces include the pressure difference between the blast and the top pressure, friction from wall area and the buoyancy caused by liquids of the hearth on the submerged coke.

The weight of the burden is usually enough to counteract the upward forces, but when the hearth occupancy exceeds a critical limit, then the burden descend becomes slower than expected due to exceeded pressure difference from top to bottom and the irregularities like hanging or chilling can arise in the blast furnace. This sometimes mistakenly blames the coke for the poor descending of burden. In another case, when the liquid level comes down to a too low value for a great time, the downward forces can become highly dominating and this can result in the slipping in which the burden descends at a very fast rate and the operational control can be lost.

The correlational research shows a negative relation between hearth occupancy and the stock level, approving the hypothesis that the burden descent is being hampered due to the increase in liquid levels.

\section{- Casting speed}

Casting or drainage refers to the process of tapping or removing hot metal and slag from the hearth through tapholes of the blast furnace. Casting is done in a regular time interval and the 
casting rate is simulated with the liquid level such that it does not approach a critical limit. The liquid levels in the hearth rise when the tapping rate of the products lags the production rate. Poor casting can result in unstable blast furnace operation and accumulation of liquids in the hearth. As a consequence there is no surprise of getting a negative outcome of regression analysis of these two parameters.

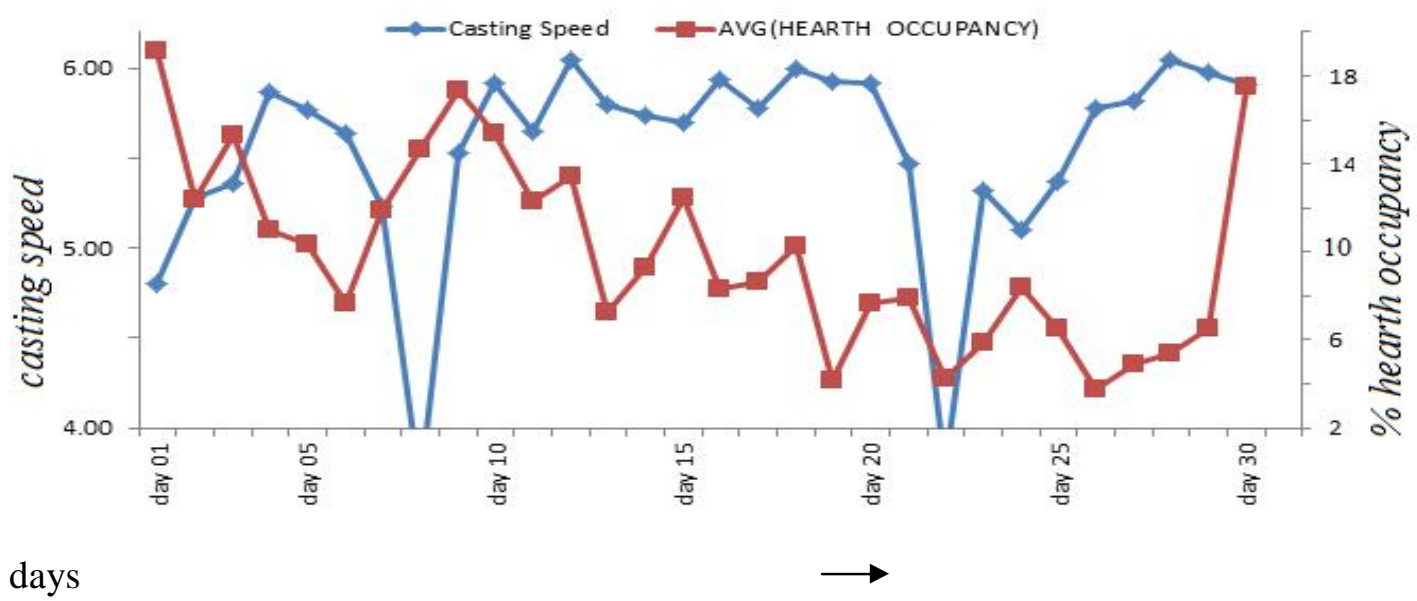

Figure4. Variation of casting speed $\left(* 10^{3}\right.$ tpd) w.r.t. average hearth occupancy (\%)

\section{CONCLUSIONS}

The main purpose of the work has been to find the factors influencing the liquid level in the hearth and to develop methods to control it and to operate the blast furnace hearth properly. Combining the knowledge based on the studies and analysis, following conclusions has been drawn

- $\quad$ Raised liquid level in the hearth was found to be direct related with the irregularities like erratic burden descent, hanging, slipping, erosion of refractory lining of walls, heat loss in bosh region, and increase in hot metal $\mathrm{Si}$ content, decrease in permeability in different regions of blast furnace and pressure imbalance in the inner atmosphere. This condition necessitates the estimation of liquid levels on real-time basis.

- $\quad$ The liquid levels in the hearth can be estimated periodically via indirect approach by using mass balance and metallurgical principles working behind the blast furnace iron making process, calculating inflow rate of charged materials and outflow rate of products, taking account of hearth geometry and its voidage percentage into considerations.

- Continuous estimation of hearth occupancy enables one to control different process parameters like casting speed, widening of drill diameter etc., so as to prevent liquid level to exceed its critical limit and get it from furnace without letting it interfere with blast furnace campaigning and stability.

- The operational control and estimated hearth condition result in optimised and efficient productivity through blast furnace iron making route along with convenience in handling process parameters.

\section{REFERENCES}

[1]. Real-time blast furnace hearth liquid level Monitoring system, By Ashish Agrawal, Swapnil C. Kor, Utpal Nandy, Abhik R. Choudhary \& Vineet R. Tripathi. 
[2]. Effect of casting parameters on permeability in lower part of blast furnace, by B. Desai, R. V. Ramna and A. Dey.

[3]. Modern blast furnace, an introduction, By M. Geerdes, H. Toxopeus, C. van derViliet.

[4]. A Study of the Heat Flow in theBlast Furnace Hearth Lining, By Maria Swartling.

[5]. Drain Rate and Liquid Level Simulation in Blast Furnace Hearth Using Plant DataBy Hemant Upadhyay and T. K. Kundu.

[6]. A. K. Biswas, Principles of Blast Furnace Ironmaking, SBA Publications, Kolkata, India, 1st edition, 2005

[7]. Determination of factors influencing the deadman position and evaluation of its impact on blast furnace lifetime, By M. O. Hattink, J. van der Stel.

[8]. Monitoring Blast Furnace Hearth, By KaleviRaipala, RautaruukkiOy.j

[9]. Model-based estimation of liquid flows in the blast furnace hearth and taphole, By Lei Shao.

[10]. J. Brannbacka and H. Saxen: 'Novel model for estimation of liquid levels in the blast furnace hearth'. 